\title{
Reformismo universitario y movilización laicista ante "La Gran Colecta Nacional Pro Paz Social" en Córdoba (Argentina)
}

\author{
University reformism and secular mobilization against "The Great \\ National Collection for Social Peace" in Córdoba (Argentina)
}

\author{
Ezequiel Grisendi \\ Programa de Historia y Antropología de la Cultura, \\ Universidad Nacional de Córdoba, \\ Instituto de Antropología de Córdoba, \\ Consejo Nacional de Investigaciones Científicas y Técnicas (Argentina)
}

\begin{abstract}
Resumen
Este artículo reconstruye el marco y principales acciones de los sectores reformistas y liberales de la Ciudad de Córdoba frente a la Gran Colecta Nacional, estrategia de avance de la Unión Popular Católica Argentina sobre la "cuestión social", desarrollada en 1919. A partir del análisis de la prensa y de algunas publicaciones periódicas, ofrecemos un panorama inicial del contexto de avance del proyecto de Monseñor De Andrea a nivel nacional y local, el éxito relativo de su articulación con el Arzobispado y con la Liga Patriótica Argentina sede Córdoba y los posicionamientos públicos de resistencia y movilización realizados por dirigentes políticos y universitarios filiados con el reformismo y con el liberalismo anticlerical. Pese a la diversidad social e ideológica de este continente, sostenemos que el rechazo a la Gran Colecta consiguió aglutinar coyunturalmente dicha heterogeneidad, activando lealtades forjadas previamente o promoviendo nuevas, a la vez que ofreció un diálogo próximo entre la Federación Universitaria de Córdoba, asociaciones liberales como Córdoba Libre o el Comité del Librepensamiento con la Federación Obrera Local. De este modo, buscamos contribuir a una ponderación situada del vínculo entre reformismo universitario y sectores obreros en Córdoba, luego de 1918.
\end{abstract}

\section{Palabras Clave}

Reformismo universitario; Catolicismo social; Liberalismo; Anticlericalismo; Cuestión social.

\footnotetext{
Abstract

This article reconstructs the framework and main actions of the reformist and liberal sectors of the City of Córdoba against the Great National Collection, a strategy for the advancement of the Argentine Catholic People's Union on the "social question", developed in 1919. From the analysis of the press and some magazines, we offer an initial overview of the progress of the Monsignor De Andrea project at the national and local levels, the relative success of its articulation with the Archbishopric and with the Argentine Patriotic League

Esta obra está sujeta a la Licencia Reconocimiento-NoComercial-CompartirIgual 4.0 Internacional de Creative Commons. http://creativecommons.org/licenses/by-nc-sa/4.0/ 


\section{Ezequiel Grisendi}

based in Córdoba and the public positions of resistance and mobilization carried out by political and university leaders affiliated with reformism and with anticlerical liberalism. Despite the social and ideological diversity of this continent, we maintain that the rejection of the Great Collection managed to unite such heterogeneity in a conjunctural way, activating previously forged loyalties or promoting new ones, at the same time that it offered a close dialogue between the University Federation of Córdoba, liberal associations like Córdoba Libre or the Freethought Committee with the Local Workers Federation. In this way, we seek to contribute to a situated weighing of the link between university reformism and labor sectors in Córdoba, after 1918.

Keywords

University reformism; Social Catholicism; Liberalism; Anticlericalism; Social question.

\section{Introducción}

La alianza entre los posicionamientos universitarios progresistas y las luchas del movimiento obrero resulta una dimensión clásica de la historiografía del reformismo universitario (Buchbinder, 2018). Sin embargo, los lazos efectivos entre los continentes estudiantiles y trabajadores han sido frecuentemente caracterizados más por la cualidad disruptiva de sus intervenciones y la persistencia de su vínculo que por las coyunturas concretas que los propiciaron y las desavenencias públicas que alentaron (Cfr. Agüero, 2016; Chabrando, 2019). Así, la aproximación de la Federación Universitaria de Córdoba a los reclamos de los sectores obreros supuso una serie de fracturas al interior del movimiento estudiantil que veía en esa posición obrerista un desdibujamiento del perfil específico de la lucha universitaria. En efecto, tan pronto se reabrieron las puertas de la universidad de Córdoba en octubre de 1918, decretando su normalización institucional y académica, las principales figuras del reformismo mantuvieron activa su cercanía con la realidad obrera, organizada desde la Federación Obrera Local (FOL). Ese prístino entusiasmo de la dirigencia reformista, motivo de enfrentamiento abierto entre fracciones estudiantiles desde 1920, intentó aunar "La Marsellesa” y "La Internacional”, pese a la creciente crítica dentro de las propias filas reformistas.

La estrecha ligazón entre universitarios reformistas y obreros, con rastros de contactos al menos desde 1917, se consolidó tras la huelga estudiantil de junio y el atentado contra Enrique Barros en el mes de octubre de 1918, proyectándose en las protestas de enero de 1919 en condena de la FOL contra la represión de la Semana Trágica (Gerdes, 2016). Al calor de las confrontaciones contra los grupos estudiantiles y de jóvenes profesionales antiliberales, aglutinados más o menos orgánicamente en torno a la Liga Patriótica Argentina o a grupos orientados por dirigentes clericales, las intervenciones en el espacio público de agrupaciones reformistas y de obreros articularon consignas fundadas en el horizonte de un reformismo social laicista, fuertemente crítico de la "caridad" y el rol jugado por las instituciones confesionales. En ese marco, la estrategia ofensiva de la Iglesia Católica 


\section{Reformismo universitario y movilización laicista ante "La Gran Colecta Nacional Pro Paz Social” en Córdoba (Argentina)}

respecto de la "cuestión social" produjo un reordenamiento interno mediante la creación de la "Unión Popular Católica Argentina", lo cual promovió un fuerte espacio de discusión entre las fuerzas del movimiento reformista. En ese sentido, la Gran Colecta Nacional Pro Paz Social de 1919, activó de una serie de repertorios políticos y simbólicos de los reformistas cordobeses y la confrontación abierta con los aliados locales de Monseñor De Andrea. A partir del análisis de las intervenciones públicas de los dirigentes reformistas, sus ecos en la prensa y las respuestas esgrimidas por sus rivales en torno a la "Gran Colecta", ofrecemos una aproximación al vínculo entre el movimiento estudiantil universitario, algunas figuras del liberalismo progresista y los sectores trabajadores, atendiendo a las disputas al interior del espacio reformista cordobés y su proyección ante la demostración de fuerza de los sectores clericales. Este trabajo pretende, así, ofrecer una aproximación a la reforma universitaria en tanto variante particular de un reformismo social que la contiene, aunque no la agota, y en un marco histórico cuya temporalidad reclama una articulación de la coyuntura de los debates y conflictos activos en 1919 como parte de un ciclo de avance de un liberalismo en clave progresista en la arena política y cultural de la ciudad (Agüero, 2017).

La renovación del catolicismo en clave social: De Andrea y La Unión Popular Católica Argentina

La estrategia social de la iglesia impulsada desde los Círculos de Obreros Católicos tomó un renovado impulsó con la llegada de Monseñor De Andrea al cargo de Director Espiritual, en reemplazo de uno de sus fundadores, Federico Grote, y de Alejandro Bunge como Presidente a partir de 1912 (Vidal, 2010; Lida, 2013). Si los Círculos supusieron un paso al frente para instalar la "armonización" del conflicto social por parte de las asociaciones católicas en el país, siguiendo los postulados de la Encíclica Rerum Novarum de 1891, el accionar de algunos dirigentes laicos especialmente comprometidos con el catolicismo social y con probada capacidad para articular relaciones con el poder político y económico, dieron lugar a una notable centralidad de esa institución en diferente jurisdicciones, tanto en el plano nacional como en los espacios provinciales (Mauro, 2015). En mayo de 1916, el VI Congreso de los Círculos ratificó la orientación social de la iglesia a una mayor dedicación de la educación popular y en favor de profundizar las medidas de acción para atenuar los impactos de la "modernización liberal". Además de la creación de nuevas instituciones en manos de figuras del laicado, De Andrea promovió fuertemente la acción entre los sindicatos de orientación católica a través de conferencias populares y otras medidas para la divulgación de la posición social de la iglesia respecto de los trabajadores (Auza, 1987).

En el contexto de la escalada de huelgas y conflictos sociales a lo largo de 1917, los gremios católicos encontraron en la Confederación Profesional Argentina una institución de interlocución y en el presbítero Gustavo Franceschi, un dirigente que diligentemente buscó desacoplar las movilizaciones más radicalizadas de los 


\section{Ezequiel Grisendi}

trabajadores aglutinados en torno al sindicalismo católico. A mediados de 1918, De Andrea presentó su renuncia a su cargo en los Círculos de Obreros lo que suponía una tensión al interior del campo católico. Sin más, apenas un año después, De Andrea asumió la dirección de la Unión Popular Católica Argentina, un emprendimiento promovido por el Episcopado, tendiente a centralizar las acciones de las diferentes asociaciones católicas, especialmente orientada a fortalecer el lugar de la iglesia en los sectores socialmente vulnerables $\mathrm{y}$, desde sus inicios, con una firme vocación de alcanzar la mayor cantidad de ciudades del territorio argentino. Resultado de la observación directa de De Andrea del funcionamiento de organizaciones católicas europeas, la Unión Popular Católica Argentina fue creada en abril de 1919, tras numerosas instancias previas fallidas por aunar criterios respecto del estatuto de la nueva asociación. En el horizonte de la UPCA, la retórica del catolicismo social resultaba omnipresente, en el mismo tono que había dominado las variadas intervenciones en el Primer Congreso Católico Diocesano realizado en octubre de 1918 en Córdoba, en parte como respuesta al desafío liberal desatado en la universidad de esa ciudad (Vidal, 2016). De Andrea, partícipe del mencionado congreso, había adelantado las directrices orientativas de su ideal de catolicismo social en las conferencias públicas desarrolladas en 1917.

Así las cosas, el proyecto de Monseñor De Andrea, imaginado como una profundización de la estrategia social del catolicismo a través de la UPCA, tomó forma a partir de una acción concreta en septiembre de 1919. Con el acuerdo de la cúpula eclesiástica argentina, la UPCA promovió la Gran Colecta Nacional Pro Paz Social, evento iniciado el 22 de septiembre y organizado para la recaudación de recursos económicos que permitirían solventar una serie de demandas sociales como por ejemplo becas para niños y niñas estudiantes, gastos de tratamientos de salud, una oficina centralizadora de servicios sociales y de sociedades de beneficencias en el país, la construcción de casas para obreros y la fundación de universidades populares destinadas a la formación de los trabajadores adultos.

La capacidad de movilización de la UPCA en todo el país permitió vencer la inicial desconfianza al proyecto de De Andrea y aglutinar el apoyo de gran cantidad de miembros de la elite social. ${ }^{1}$ Esa estrategia de parte de De Andrea supuso, al mismo tiempo, avanzar en la disputa con los sectores liberales por ofrecer alternativas a las problemáticas sociales, bloquear el fortalecimiento de las posiciones de izquierda, anarquistas y socialistas, entre el proletariado $y$, finalmente, congregar a los grupos políticos vencedores en el '80 pero desplazados por el yrigoyenismo en torno a una alianza con la iglesia en vistas de un "encauzamiento" de las opciones democráticas abiertas en 1912 y confirmadas en 1916. En efecto, la proyectada colecta fue menos novedosa por el objetivo caritativo proyectado a las elites que por la ambiciosa escala territorial anhelada por sus organizadores (Lida, 2013: 72).

\footnotetext{
${ }^{1}$ En la conferencia sostenida por De Andrea en 1917 en la sede del Instituto Popular de Conferencias, perteneciente al diario La Prensa, su argumento se concentró en impulsar a los sectores dominantes argentinos a optar por la mejor "orientación" de su accionar frente a las clases trabajadoras a fin de disolver las salidas "revolucionarias" (Lida, 2013)
} 


\section{Reformismo universitario y movilización laicista ante "La Gran Colecta Nacional Pro Paz Social” en Córdoba (Argentina)}

La estrategia de la Gran Colecta fue la de diseminar "colaboradores" por los barrios de las ciudades, recorriendo las calles apuntando las donaciones de cada vecino. La primera etapa, realizada en el mes de septiembre, y la segunda en diciembre, arrojaron una recaudación importante aunque menor a lo imaginado inicialmente. Pese a ello, la fortaleza de la empresa dirigida por De Andrea en la UPCA, coordinada por Alejandro Bunge desde los Círculos de Obreros Católicos, se manifestó con un alto grado de coherencia y solidez en la convocatoria "por la paz social", que significó prontamente la mansa subordinación de los sectores obreros a la patronal y una apuesta por la despolitización de los sectores de la juventud, especialmente activos en el espacio público de las ciudades universitarias desde 1918 (Ballent, 2014). La amenaza de "guerra social" y "disolución nacional" con la que De Andrea supo agitar de manera eficiente al auditorio del teatro Grand Splendid de Buenos Aires al presentar la convocatoria de la "Gran Colecta" que confirmó que la movilización de la fibra religiosa católica ya no alcanzaría para evitar el "colapso argentino" (Halperín Dongui, 1999), no pasó inadvertida entre los sectores eclesiásticos del resto del país, advertidos de que la UPCA buscaba articular y controlar las sociedades de beneficencia existentes. Sin embargo, y pese al ímpetu "nacional" de la Gran Colecta, parece que la misma no fue especialmente exitosa fuera de la ciudad de Buenos Aires, donde logró captar la mayor cantidad de recursos. En otras ciudades, la Gran Colecta pareció funcionar como un revulsivo para la militancia católica, en ocasiones retraída, y para las fuerzas liberales que la identificaron como un nuevo avance de la iglesia (Lida, 2015).

\section{La UPCA y la Gran Colecta Nacional en Córdoba}

Sobre aquél marco general del campo católico a nivel nacional, la dinámica propia de las fuerzas en Córdoba permiten comprender las aristas sobre las cuales el proyecto de De Andrea vino a inscribirse. La tradición colonial de las sociedades de beneficencia confesionales en Córdoba se conecta tanto con el modelo cofradial y de hermandades, propiamente activo durante el período colonial, como con las asociaciones laicas pro-católicas que se fortalecieron en la segunda mitad del siglo XIX, en parte para contrarrestar las iniciativas liberales y anticlericales, en parte para profundizar la conexión entre la religión católica y las asociaciones de trabajadores (Vagliente, 2015). Este entramado de asociaciones civiles tendientes a ponderar un estrecho vínculo entre catolicismo y sectores subalternos, incluyó entre sus miembros a figuras de la elite política y social que encontraron en ese tipo de instituciones, la variante necesaria para atender a los conflictos propios de una sociedad en transformación. La Sociedad de Beneficencia, integrada por las damas de las familias encumbradas, fue creada en 1856 y supo incluir entre sus intereses el trabajo en escuelas, hospitales y asistencia a mujeres y niños. Entre los integrantes de los círculos dirigentes de aquella asociación, se contaban previsiblemente católicos confesos pero también algunas figuras ascendentes identificadas con el liberalismo, los cuales fueron integrados a la Sociedad de Beneficencia en calidad de 


\section{Ezequiel Grisendi}

benefactores (Río, 1967). Pero si esa posición de la beneficencia católica había transitado, aunque con embates, los años de mayor fuerza del liberalismo en la Córdoba del último tercio de siglo, las más incisivas críticas que pusieron en tensión su centralidad provinieron no sólo de aquellos liberales partidarios de una intervención estatal sobre los problemas sociales, sino también de quienes, aúnque católicos y partícipes de la Sociedad, aspiraban a una solución de los conflictos desatados por la modernización pero en clave de un "catolicismo social" de nuevo cuño.

La acción social de las fuerzas conservadoras en la provincia de Córdoba tiene un capítulo privilegiado a partir del núcleo de dirigentes católicos nucleados en torno a la figura del gobernador Félix T. Garzón. Juan Félix Cafferata y Arturo M. Bas, representan expresamente esa línea de aproximación de los grupos dirigentes católicos a las soluciones posibles para la conflictividad social en constante aumento en los años del Centenario. Cafferata, primero diputado provincial y luego nacional, consiguió los consensos necesarios para que su proyecto de ley sobre "casas para obreros en la capital de la república" fuera finalmente aprobado, constituyéndose así, la Comisión Nacional de Casas Baratas. Figura paradigmática del pensamiento social cristiano de comienzos de siglo, Cafferata participó, inicialmente, en la Liga Democrática Cristiana junto a otros referentes de esa vertiente política, además de sumarse al proyecto de los Círculos de Obreros Católicos, experiencia a partir de la cual formaría buena parte de sus proyectos sobre legislación social y obrera.

La creación de la sede cordobesa de la UPCA recibió prontamente el apoyo del obispo Fray Zenón Bustos quien asumió un rol activo en la defensa de la posición de la iglesia ante las críticas de los sectores liberales. Lejos de retraerse a la esfera eclesiástica, la impronta del accionar de Zenón Bustos no sólo fue acompañar la creación de nuevas parroquias en la campaña cordobesa sino contribuir al fortalecimiento de las nuevas instituciones educativas confesionales en los barrios de la ciudad de Córdoba, robustecer el accionar de los Círculos de Obreros y estrechar el diálogo con la dirigencia política laica. Si bien un número importante de hombres de la iglesia habían participado en el juego político a propósito de coyunturas electorales durante la primera década del siglo al amparo de Zenón Bustos, paulatinamente el obispo impugnó la idea de la injerencia de los sacerdotes a la arena política. Esto no impidió, sin embargo, el accionar político de Bustos en tanto referente de la jerarquía eclesiástica cordobesa (Lierbscher, 1989). El rechazo de Bustos de la Ley Sáenz Peña inclinó su apoyo a Cárcano y la Concentración Popular, en primera instancia, y pese a su posición contraria al radicalismo, contribuyó con su respaldo al gobierno de Eufrasio Loza, reconocido católico, electo como gobernador provincial en 1915.

Zenón Bustos, quien había hecho público su rechazo al movimiento estudiantil reformista y a las acciones de huelgas y tomas de los edificios universitarios durante 1918, abrazó rápidamente la propuesta de la Gran Colecta en Córdoba. El diario del arzobispado, "Los Principios", ilustra en sus páginas la constitución del Consejo de la UPCA en Córdoba y sus actividades desde los primeros días del mes de octubre de 


\section{Reformismo universitario y movilización laicista ante "La Gran Colecta Nacional Pro Paz Social” en Córdoba (Argentina)}

1919. Las conferencias populares llevadas a cabo en las parroquias de la ciudad ponderaban, especialmente, el agotamiento del liberalismo "comprobado por el desastre bélico mundial” y la necesidad de una reactivación moral católica. En ese horizonte, la creación de los "Centros de juventud" y la articulación entre la UPCA y los Centros de Estudiantes Católicos de la universidad, permitieron una ofensiva de la acción católica por interceder en el mundo estudiantil, donde el reformismo era fuerte (Schenone, 2011).

Si bien la UPCA no parece haberse consolidado en Córdoba, aún luego del convocante congreso nacional de la UPCA de 1922, la visibilidad de las intervenciones públicas de la Gran Colecta Nacional durante 1919 llamaron la atención de otras organizaciones (Vidal, 2016). Así, el proyecto de De Andrea en Córdoba se fortaleció en los años siguientes, sumando importantes sustentos desde diferentes sectores de la elite. Además de este respaldo del obispado cordobés, la Gran Colecta resultó significativamente atractiva para quienes, en nombre de las patronales, demandaban una reducción de la conflictividad obrera. El corpus legal represivo de la protesta obrera vigente, tanto la Ley de Residencia como la Ley de Defensa Social, no impidieron, sin embargo, la conformación de instituciones y grupos de choque que defendían la predominancia social de las elites. En efecto, no sorprende que muchos colaboradores de la UPCA en Córdoba hayan estrechado sus relaciones con la Asociación del Trabajo y la Liga Patriótica Argentina². Menos presentes que en Buenos Aires, sin embargo, cumplieron un rol preponderante en los días de la Gran Colecta (Rapalo, 2012: 30-31). Los periódicos locales repasan algunos de los nombres afiliados a la Asociación del Trabajo con vinculaciones con la UPCA, y con incidencia en la universidad como los casos de Luis G. Martínez Villada o Sofanor Novillo Corvalán. En el caso de Martínez Villada, abogado y declarado enemigo de los reformistas en 1918, fue de los primeros en objetar ante el Decanato de la Facultad de Derecho, la admisión de los nuevos profesores y consejeros como Deodoro Roca o Arturo Orgaz, fue recurrentemente indicado como parte de la dirigencia de la Liga Patriótica en Córdoba.

El contexto del recrudecimiento de la ofensiva patronal y del accionar violento de la Liga Patriótica fue, para el caso de Córdoba, el de un ciclo de conflictividad social primordialmente dirigido por las asociaciones gremiales de fuerte presencia pública. En 1917, un nutrido número de dirigentes sindicales, de orientación socialista, e integrados en la Federación Obrera Local, se integraron a los mitines convocados por "Córdoba Libre" (PIanetto, 1991; Agüero, 2016) y otras agrupaciones liberales y aliadófilas en contra de la Gran Guerra. Ese sustrato de solidaridades entre el movimiento obrero y referentes del reformismo universitario, tiene sus correlatos en los acompañamientos mutuos, inicialmente en la huelga de los obreros del calzado que, desatada en los meses de julio y agosto de 1918, recibió el aliento de Enrique Barros y Deodoro Roca. Esa conexión no dejará de

\footnotetext{
2 Como advirtió McGee Deutsch (2003), la estrategia social de la UPCA integró rápidamente a encumbrados miembros de la Liga Patriótica a nivel nacional y despertando especial interés entre las ramas femeninas de la organización.
} 


\section{Ezequiel Grisendi}

intensificarse con la huelga general decretada en enero de 1919 y las sucesivas movilizaciones que llevaron adelante los trabajadores de las empresas tranviarias y de la empresa de energía (Gordillo, 1988).

A lo largo de 1919, y luego de unas agitadas semanas a propósito de las elecciones municipales, los conflictos entre las fuerzas policiales y los obreros se multiplicaron, y la intervención de los jóvenes universitarios en apoyo de los trabajadores desembocó en no pocas presentaciones de los líderes reformistas contra la represión estatal desmedida y contra el accionar "anti-obrero" y "anti-maximalista" de la Liga Patriótica. A partir del mes de marzo, la disputa pública entre los principales candidatos a integrar el Consejo Deliberante de la ciudad de Córdoba, ganó lugar en los periódicos locales. Significativamente, esta compulsa electoral municipal configuró un escenario donde las confrontaciones no sólo tensionaban modos de ejercer el poder comunal sino referencias a los sucesos que pocos meses antes habían contrapuesto buena parte del sector obrero agrupado en la Federación Obrera Local con apoyo de la Federación Universitaria de Córdoba, por un lado, y los grupos más reaccionarios que justificaron el accionar represivo de enero de 1919. Si bien las fuerzas enfrentadas en las elecciones a realizarse en el mes de julio de ese año prolongaban en buena medida las que apenas un año antes, en 1918, habían consagrado al conservador León S. Morra como intendente municipal, la confrontación por la conformación del Consejo activó rivalidades por entonces atravesadas por los resultados de la "cuestión universitaria", en la mirada de corto plazo, pero alentada por disputas más antiguas, coyunturalmente remozadas. Es que, muchos de quienes disputarían el voto municipal habían tomado participación en los debates que desembocaron primero en las intervenciones de la universidad y finalmente en la reforma de los estatutos de la "Casa de Trejo" (Grisendi, 2018).

\section{Los reformistas y la movilización liberal contra la Gran Colecta Nacional}

Emilio R. Biagosch, estudiante avanzado de abogacía para el año 1919, expresaba, en la editorial de la Revista del Centro de Estudiantes de Derecho de Córdoba, la llegada de un "momento espiritual", forjado por la "nueva humanidad" que los bríos de la reforma universitaria de 1918 habían interpretado mejor el lazo entre "Juventud y Pueblo". Para el entonces, director de la mencionada publicación estudiantil, el "pacto" entre los jóvenes universitarios y los sectores populares había cumplido con sostener el reclamo en las aulas y, por consiguiente, era el justo momento para apoyar la lucha social más amplia. Esa versión radicalizada de los postulados reformistas (Bustelo y Domínguez Rubio, 2017) atravesaron el discurso de estudiantes y también de numerosos egresados y profesionales que acompañaron la celebración del primer aniversario de la reforma en junio de 1919. Impugnadas como "expresiones del maximalismo" en las páginas del diario católico "Los Principios", las manifestaciones públicas a favor de las transformaciones iniciadas en los claustros universitarios en 1918 provocaron sucesivas reacciones de rechazo entre aquellos que veían modificarse las correlaciones de fuerzas que 


\section{Reformismo universitario y movilización laicista ante "La Gran Colecta Nacional Pro Paz Social” en Córdoba (Argentina)}

poco tiempo antes dominaban. Así, la "amenaza social" que representó la Reforma entre una porción de la elite cordobesa pareció menos vinculada a la efímera, aunque intensa, prédica revolucionaria de algunos de sus voceros y más próxima al crítico desafío a las pautas de sociabilidad y a la legitimación de las posiciones sociales establecidas de los grupos dominantes (Devoto, 2005).

Este cuadro de situación permite inscribir política y simbólicamente el alineamiento de los sectores conservadores con la UPCA e interpretar las movilizaciones activadas por los referentes cordobeses del reformismo universitario. En efecto, la Gran Colecta interpeló a los dirigentes del reformismo universitario en todas las casas de altos estudios del país. Para aquellos nucleados en torno a la revista porteña "Bases", la convocatoria de De Andrea representaba el "Gran Chantaje Católico", no sólo porque detrás de la promoción de la caridad cristiana avizoraban un recrudecimiento reaccionario contra los avances liberales en términos de políticas sociales, sino que denunciaban la afrenta a la democracia que suponía el "arreo de votos conservadores" en vistas de las elecciones de 1920. Esa posición de los editores de "Bases" evidencia el rechazo de la Gran Colecta que compartieron los estudiantes porteños con los integrantes de las Federaciones Universitarias de La Plata y Córdoba. En un Manifiesto publicado en octubre de 1919, los platenses enfatizaban la necesidad que

"las multitudes proletarias levanten su voz, clamando por una mayor justicia social...[y ante ese reclamo] la clase aristocrática del país, convocada por la iglesia católica, ensaya una solución...según los improvisados sociólogos y estadistas de la gran colecta nacional, todo quedará resuelto con recolectar unos cuantos millones para luego tapar la boca y aplacar el furor del pueblo hambriento...”3

Los dirigentes reformistas cordobeses de la FUC, emitieron su propio manifiesto, acompañando el tono de la denuncia de sus pares de Buenos Aires y La Plata. Dirigiéndose a los "ciudadanos", el texto advertía la estrategia ensayada por quienes eran identificados como "la reacción". Para los firmantes, entre ellos el Presidente de la FUC, Enrique F. Barros, además de Horacio Miravet, Cortés Plá o Jorge Orgaz, la recaudación del dinero era un ejemplo claro de que las armas de los "contrareformistas" no eran las ideas sino "el capital", la sola lectura de la convocatoria de la colecta Pro Paz Social, permitía observar el objetivo conservador de sus promotores: "calmar las fieras hambrientas". En ese sentido, los reformistas cordobeses evidenciaban, en la estrategia de las agrupaciones católicas, una combinación de atracción a los sectores sociales altos a través de la colecta nacional y la condena violenta a quienes desconfiaran del fiel propósito, encarnada esta última en el accionar de la Liga Patriótica Argentina en Córdoba.

Como lo expusieron los estudiantes del Centro de la Facultad de Medicina de Córdoba, la Gran Colecta no era sino un intento más del "Clérico-capitalismo",

\footnotetext{
${ }^{3}$ Bases, Año I, Vol. 5, 1919, pg. 2.
} 


\section{Ezequiel Grisendi}

reunión articulada de la "burguesía argentina y el clericalismo argentino", estrategia contra la cual combatiría la "la juventud universitaria...que tiene el deber de velar por la salud moral del pueblo"4. Las acciones ejecutadas por los estudiantes reformistas no sólo incluyeron la denuncia pública de la Gran colecta y sus principales animadores locales, rápidamente identificados como los "enemigos de la Reforma", sino que dispusieron el boicot contra los comercios particulares que apoyaran con recursos la Gran Colecta, mítines informativos para la población ${ }^{5}$ y la expulsión de todo estudiante federado que esté vinculado con la Liga Patriótica Argentina ${ }^{6}$.

En la inauguración de la Casa del Estudiante7, espacio auspiciado por la FUC y creado como resultado de los reclamos de los alumnos por un local particular para la discusión de los asuntos del "gremio estudiantil", Arturo Orgaz, ofreció la conferencia "La Gran Colecta y la libertad del pueblo argentino". En aquella ocasión, a pocos días de realizarse los actos centrales de la Gran Colecta, el dirigente reformista recordaba ante un público predominantemente estudiantil, como la acción de los referentes de la UPCA dañaba la democracia política y universitaria. Para Orgaz, detrás de aquellos que proclamaban la ayuda a los sectores más desfavorecidos por el desastre económico, se encontraban los grupos más poderosos de la sociedad, los "derrotados del 18", con una referencia al contingente ambiguo de militantes católicos, liberales moderados contrarios a la FUC y los que abiertamente habían rechazado la reforma de los estatutos universitarios. ${ }^{8}$

No muy lejos del local que albergó el discurso de Orgaz, se reunió el mismo día, la asamblea del muy activo Comité del Libre Pensamiento. Resultado local del importante Congreso de Libre Pensamiento realizado apenas un año antes en la ciudad, los promotores de la "propaganda librepensadora", aprobaron la organización de los integrantes en comisiones para trabajar en los diversos frentes anti-clericales que aglutinaban sus acciones (Nuñez, 2017). Además de intervenir en cuestiones de supresión de imágenes religiosas en oficinas públicas, de la incentivación de medidas de salud pública y de eliminación de la enseñanza

\footnotetext{
${ }^{4}$ Bases, Año I, Vol. 5, 1919, pg. 3.

${ }^{5}$ La Voz del Interior, Córdoba, 3/10/1919. En tres de los puntos más importantes de la ciudad, se apostaron escenarios para que los oradores representantes de la FUC, expusieran sobre la necesidad de rechazar el proyecto de la Gran Colecta: En barrio General Paz, Carlos Correa Uriburu y José Camblor; en Alta Córdoba frente a la estación de Ferrocarriles, Américo Aguiar Vázquez y Jorge Orgaz; en el centro de la ciudad, en 9 de julio y San Martín, Miravet y Eduardo García Araoz.

${ }^{6}$ Ídem.

${ }^{7}$ Como alternativa al modelo de internado estudiantil anglosajón vigente en la Universidad platense, La Casa de los Estudiantes fue proyectada durante el Primer Congreso Nacional de Estudiantes Universitarios que sesionó en Córdoba en julio de 1918, al calor de los sucesos que desembocaron en las huelgas un par de meses después (Gentile y Vallejo, 1999: 103). En buena medida, la posibilidad de contar con un espacio especialmente dedicado a los estudiantes acogió, rápidamente, la idea de conformar un anexo que sirviera de hospedaje económicamente accesible para los estudiantes que llegaban a Córdoba desde otras latitudes. En julio de 1919, la FUC designó una comisión integrada por Alfredo Brandán Caraffa, Julio Barros y Oscar Orgaz, para entender en la redacción del reglamento interno de la Casa del Estudiante, incluyendo la posibilidad de ofrecer albergue a alumnos de otras provincias o países vecinos. La Voz del Interior, 2 de julio 1919.

${ }^{8}$ La Voz del Interior, Córdoba, 1/10/1919.
} 


\section{Reformismo universitario y movilización laicista ante "La Gran Colecta Nacional Pro Paz Social” en Córdoba (Argentina)}

religiosa, los librepensadores se pronunciaron contra la Gran Colecta Nacional “...en acuerdo con las Federaciones universitarias y obreras de todo el país...”, a través de un plan de boycott contra quienes apoyaran la colecta, la organización regular de conferencias y la expansión del Comité a las distintas seccionales de la ciudad.

El refuerzo de la posición de los sectores del liberalismo progresista universitario y de trabajadores reunidos en torno a la FOL en contra de la Gran Colecta Nacional se expresó en el concurrido mitín convocado por dirigentes del reformismo y de los gremios para repudiar el "Gran cuento Nacional", como lo catalogaban los promotores del encuentro. Rebrote clericalista, afirmaban las notas periodísticas partidarias de los reformistas, la convocatoria de la colecta confirmaba el espurio vínculo entre los sectores de las elites beneficiadas por el "metal de los mercaderes" y la iglesia, que pretendía usar esos recursos para "comprar fieles con casas para obreros". Convocado el encuentro público para el 6 de octubre, los voceros de la FUC anunciaban la alianza con el "...proletariado por una comunidad de intereses...", existentes desde un tiempo anterior a los sucesos de 1918, y reactualizados mediante eventos que reunieron a los universitarios federados y al "pueblo trabajador", como en la movilización del 14 de julio de 1919 por el centro de la ciudad, entonando "La Marsellesa".

En tan encendido discurso anticlerical, los integrantes de la asociación "Córdoba Libre" insistieron con el planteo para que la "cuestión social" se resolviera, menos por el beneplácito de las dádivas de los sectores opulentos que por la aplicación de un programa efectivamente renovador de las relaciones sociales: "Dese a cada hombre tierra, y désele a cada hombre libertad" 9 . El ataque contra la concentración de riqueza, y expresamente contra la vigencia del latifundio, advierten rápidamente sobre la inclusión de los presupuestos georgistas entre los partidarios liberales de la mencionada agrupación político-cultural (Grisendi, 2015). El seno de "Córdoba Libre", si bien no exclusivamente integrado por reformistas, si estuvo principalmente animado por un buen número de autodenominados "hombres libres" que acompañaron fervorosamente el levantamiento estudiantil de 1918 y que, frente a la estrategia de la UPCA, retomaron un lugar expectable en el debate respecto de la Gran Colecta.

Congregados por "Córdoba Libre", la FUC y la FOL en los distintos barrios de la ciudad, universitarios, obreros o profesionales liberales, el 6 de octubre marcharon contra la Gran Colecta, llamando explícitamente a boicotear el proyecto de Monseñor De Andrea y a combatir la represión de la Liga Patriótica Argentina. En barrio San Martín, en el noroeste de la ciudad, Aldo Péccora y Francisco Mulet encabezaron el mitín anti-clerical; en el barrio Alta Córdoba, hacía el norte, Américo Aguiar Vázquez y Cortés Plá, presidieron el encuentro; similares condiciones se replicaron en otros puntos de la ciudad. La convocatoria desembocó en la céntrica Plaza General Paz donde se realizaron las principales conferencias. Con esmerado detalle, en la prensa local se indicaban los nombres de quienes propiciarían esa

${ }^{9}$ La Voz del Interior, Córdoba, 5/10/1919 


\section{Ezequiel Grisendi}

"batalla cívica" contra la propuesta de la Gran Colecta, especie de traducción del debate ideológico en el plano de la acción colectiva en las calles de la ciudad. Así, se consignaron como "comisarios de la columna", principales figuras que conducían el grueso de la movilización por el centro de la ciudad. Entre ellos, se vislumbraron figuras más o menos cercanas al reformismo como Sebastián y Luis Soler, Héctor y Juan Carlos Roca, Jorge y Alfredo Orgaz, los hermanos Sayago o Ceferino Garzón Maceda. Entre quienes tenían a su cargo la custodia de la "acera derecha" de la movilización encontramos importantes dirigentes del reformismo universitario como los hermanos Alfredo y Carlos Brandán Caraffa o Augusto y Luis Despontín.

Luego del recorrido por las calles céntricas de Córdoba, el mitin se convocó en la Plaza General Paz donde, entre los conferencistas se advirtieron representantes de la FUC (Ruíz Gómez), de la Sociedad Georgista (Alberto Durrieu), del Comité de Libre Pensamiento (José Ponsa), de la Federación Obrera Local (el dirigente comunista, Miguel Contreras) y el reformista y militante socialista, Jorge Orgaz. Desde aquella plaza, las columnas de manifestantes se trasladaron hasta la Casa del Estudiante de la FUC, en calle Rivera Indarte, donde el escenario estuvo reservado a las figuras consagradas del movimiento reformista: Taborda, Barros, Deodoro Roca, Arturo Orgaz, Capdevila, Soler, Aguiar Vázquez y Biagosh. Así, entre el público movilizado, se advertían no sólo los jóvenes universitarios, sino un gran número de integrantes de las "clases proletarias", como lo notaba la convocatoria de la Sociedad Unión Obrera Carpinteros y Anexos, pero también aquellos miembros de sectores medios filiados en la Sociedad Georgista o la Unión de Almaceneros Minoristas, preocupados por el endurecimiento de su situación ante la retracción del consumo obrero. ${ }^{10}$

La demostración de fuerza del arco de agrupaciones movilizadas el 6 de octubre (el diario anotaba más de 7000 personas) encontraron en la Gran Colecta la mayor afronta de los sectores clericales contra la democracia, presentada como horizonte político insoslayablemente unido a la causa universitaria de 1918. En la mirada de las principales figuras contrarias al proyecto de De Andrea, los sectores antireformistas, y más ampliamente anti-liberales, habían conseguido reunir, tras la

"ingenua apariencia" de la Gran Colecta, el pacto entre jerarquía eclesiástica y elite, que aquellos venían a denunciar. "Una nueva batalla de la Reforma", titulaba el periódico "La Voz del Interior", evidenciando cuanto de lo conseguido por el reformismo al interior de los claustros un año antes, debía ser validado en la arena pública respecto de sus rivales pero no sólo sobre la base de estudiantado universitario sino ampliando su base de sustento a otros colectivos que compartían aquella necesidad de "reforma social". Así, en el mitin mencionado no sólo se destacaron los discursos de Arturo Orgaz o Sebastían Soler, sino que fueron objeto de "encendidos aplausos" un dirigente del Partido Socialista, como Pedro S. Linossi, el obrero Manuel Gordo o la dirigente de "Córdoba Libre", sección femenina, Ofelia Grandoli.

${ }^{10}$ La Voz del Interior, Córdoba, 20/07/1919 y 7/10/1919. 


\section{Reformismo universitario y movilización laicista ante "La Gran Colecta Nacional Pro Paz Social” en Córdoba (Argentina)}

El éxito relativo de la Gran Colecta en Córdoba puede medirse menos en función del dinero recaudado y más por la demostración de la fuerza de De Andrea y su UPCA para regimentar las asociaciones católicas detrás de un proyecto centralizado pero, al mismo tiempo, se transformó en el centro de las críticas del reformismo. Roca, Orgaz, Bermann o Taborda, desde el Comité de Agitación Liberal (que continuará activo al menos hasta 1922), recordaban que en esa Gran Colecta, los "enemigos de la reforma de 1918" venían no sólo por la universidad sino ansiaban controlar lo "único sagrado que tiene Córdoba: su pueblo".

Esa invocación al "pueblo" esgrimida por los principales referentes del reformismo fue, sin embargo, motivo para que algunos "compañeros de ruta" le recordaran la necesidad de enfrentar al "común enemigo" con mayor fortaleza y menos paciencia que la demostrada. En los días previos a los mítines convocados por "Córdoba Libre" y la FOL para octubre, el escritor Juan Antonio Ahumada invitaba a Enrique Barros a que la FUC movilizara los estudiantes ante la afrenta que suponía la Gran Colecta ${ }^{11}$. Las críticas liberales no tardaron en encontrar fuertes respuestas desde las páginas de "Los Principios" (Vidal, 2010) y, si bien las intervenciones reformistas contra la acción de la UPCA se sucedieron durante octubre, rápidamente los debates públicos cambiaron su eje, en buena medida ante el muy escaso éxito de la Gran Colecta en Córdoba.

\section{Conclusiones}

Si el proyecto de la Gran Colecta Nacional y de constitución de la UPCA supusieron ofrecer una salida posible a la conflictividad social y al desprestigio de los sectores socialmente encumbrados mediante una reconfiguración del rol jugado por la militancia católica y su acción social, el relativo fracaso de aquellos objetivos no se evidencian en los recursos económicos movilizados ni en la notable visibilidad pública de sus promotores, sino en la fragilidad de la institución dirigida por De Andrea y su incapacidad de constituirse en un moderador entre el proyecto social de la iglesia y las contradicciones sociales y culturales, que no dejaron de tensionarse en los primeros años de entreguerras (Lida, 2015: 89).

En el caso de Córdoba, ese marco impactó sobre el arco de solidaridades que había reunido a los liberales que acompañaron al reformismo universitario, activando rechazos de diferente tono contra la Gran Colecta. Asimismo, quienes habían confrontado con los reformistas, apoyaron la experiencia de la UPCA y la empresa de De Andrea. En cualquier caso, estos alineamientos lejos estuvieron de corresponderse con posiciones fijas, tanto al interior del reformismo como en su relación con las fuerzas políticas orgánicas. Entre las filas del reformismo encontramos, tempranamente, a quienes siguieron la línea de la FUC y eventualmente prosiguieron una variante radicalizada hacia la izquierda en los años inmediatamente posteriores a 1918; otros, quienes desde un ala liberal moderada

${ }^{11}$ La Voz del Interior, 1/10/1919. 


\section{Ezequiel Grisendi}

añoraban una universidad renovada pero que, vistos los sucesos de la toma del Rectorado, las huelgas y las ambiciones de revolucionarias de algunos dirigentes estudiantiles, propiciaron una reforma estrictamente universitaria, atenuando las ambiciones de una reforma social más vasta.

Aquella pluralidad al interior del movimiento reformista no oculta la diversidad de posiciones políticas de quienes acompañaron sus reclamos luego de 1918. Como advirtiera Gardenia Vidal, la relación entre los líderes estudiantiles y la dirigencia partidaria radical describió un trazo ambivalente a lo largo de los años, desde el acercamiento al yrigoyenismo a nivel nacional, pasando por el distanciamiento con la dominante fracción azul conservadora a nivel provincial, hasta un acompañamiento de algunos dirigentes que asumieron como propio el combate anticlerical y a favor de una democracia social que los reformistas propugnaban. En el caso de los dirigentes y militantes del Partido Demócrata, se contaron no pocos que se acoplaron a los eventos de 1918 desde sus inicios, en virtud de su pertenencia a asociaciones liberales como Córdoba Libre o el Comité de Librepensamiento, en la medida que su rumbo no se recortó como emprendimiento del radicalismo. Finalmente, si bien la presencia del socialismo en tanto conjunto ideológico y político es muy notable, sus representantes vinculados al reformismo en Córdoba contaron tanto con dirigentes obreros como con abogados, médicos o comerciantes. El trabajo de Ofelia Pianetto (1991) nos ofrece una clave interpretativa sobre la relación entre reformismo universitario, política partidaria y movimiento obrero: para la autora, la notable vigencia de las formas políticas facciosas y clientelares del siglo XIX en ese primer cuarto del siglo XX, explicarían la pervivencia de una "cultura política hispánica" de larga duración en el electorado, en general, y en los sectores trabajadores, en particular. Las opciones de izquierda o progresistas no habrían sido atractivas para esos grupos sociales, cooptados por las opciones políticas tradicionales demócratas o radicales. Sobre esta sugestiva hipótesis podría pensarse en los propios límites de la opción reformista como una alternativa política concreta para los sectores medios y trabajadores, cuyos dirigentes se debatieron entre el Partido Socialista (y luego socialista internacional) y las demás fuerzas políticas. Las coyunturas de mayor cercanía entre estudiantes y trabajadores en los años inmediatamente posteriores a 1918, coincidieron con la apertura de los líderes reformistas a pensar su movimiento social (Tcach, 2012) con un horizonte de reforma social. La contracción de ese panorama a un reformismo solamente universitario, aisló al grueso de los reformistas de la confrontación pública más amplia, en torno a reclamos del gremio estudiantil. Para Roca, para quien en los años treinta el reformismo no solamente no podía continuar bajo la bandera del "anticlericalismo" sino que ya debía ser "antifascista", advertía que aquella clase media que en 1918 no se resguardó sus anhelos sino que abrigó una potencia de transformación profunda de la sociedad y de la situación de los obreros en ella, había afinado "con más precisión su puntería en la historia". 


\section{Reformismo universitario y movilización laicista ante "La Gran Colecta Nacional Pro Paz Social” en Córdoba (Argentina)}

Bibliografía

Agüero, A. C. (2016) “Córdoba. 1918, más acá de la reforma” en Gorelik, A. y Peixoto, F. A. (comp.) Ciudades sudamericanas como arenas culturales, Siglo Veintiuno Editores, Buenos Aires, pp. 96-115.

Agüero, A. C. (2017) "Del tiempo y la ciudad. Córdoba, 1918 y la reforma universitaria" en AAVV, La universidad reformada. Hacia el centenario de la Reforma Universitaria de 1918, Eudeba-OEI, Buenos Aires.

Auza, N. (1987) Aciertos y fracasos sociales del catolicismo argentino, Tomo II, Editorial Docencia, Buenos Aires.

Ballent, A. (2014) "La iglesia y la vivienda popular. La Gran Colecta Nacional de 1919”, en Ballent, A. y Liernur, J. F. La casa y la multitud. Vivienda, política y cultura en la Argentina Moderna, Fondo de Cultura Económica, Buenos Aires.

Bustelo, N. y Domínguez Rubio, L. (2017) "Radicalizar la Reforma universitaria: la fracción revolucionaria del movimiento estudiantil argentino (1918-1922)", Anuario Colombiano de Historia Social y de la Cultura. Vol. 44, n‥ 2, jul.-dic.

Buchbinder, P. (2018) "La Reforma Universitaria en vísperas de su centenario: notas sobre su historiografía”, Boletin del Instituto de Historia Argentina y Americana, "Dr. Emilio Ravignani", Nr. 49.

Chabrando, V. (2019) Obrerismo y Reforma. La protesta entre las aulas y las calles, Editorial de la UNC, Córdoba.

Devoto, F. (2005) Nacionalismo, fascismo y tradicionalismo en la Argentina moderna. Una historia, Siglo Veintiuno Editora Iberoamericana, Buenos Aires.

Gentile, E. y Vallejo, G. (1999) “De los Internados al Hogar estudiantil. El hábitat en los proyectos pedagógicos de la UNLP (1905/10-1924)" En Biagini, H. (comp.) La Universidad de La Plata y el movimiento estudiantil, Edit. UNLP, La Plata.

Gerdes, T. (2016) La Semana Trágica y la perspectiva del catolicismo sobre la cuestión social en Río de la Plata, 1880-1919, EDUVIM, Villa María.

Grisendi, E. (2015) “Contra nuestro feudalismo: Intelectuales y política en la expansión del georgismo en Argentina (Córdoba, 1914-1924)”, Nuevo Mundo, Mundos Nuevos, Diciembre 2015, EHESS, Paris.

Grisendi, E. (2018) "Nuestro kulturkampf. Derivas políticas e intelectuales del reformismo universitario en la Córdoba de entreguerras", en Bacolla, N. y Martínez, I. (eds.) Universidad, elites y política. De las reformas borbónicas al reformismo de 1918, HyA Ediciones-UNR, Rosario. 


\section{Ezequiel Grisendi}

Gordillo, M. (1988) El movimiento obrero ferroviario desde el interior del país (1916-1922), CEAL, Buenos Aires.

Halperin Dongui, T. (1999) Vida y muerte de la República Verdadera (1910-1930), Ariel, Buenos Aires.

Lida, M. (2013) Monseñor Miguel De Andrea. Obispo y hombre de mundo (18771960), EDHASA, Buenos Aires.

Lida, M. (2015) Historia del catolicismo en la Argentina entre el siglo XIX y el XX, Siglo XXI Editores, Buenos Aires.

Lida, M. (2016) "Círculos de Obreros, nación, masculinidad y catolicismo de masas en Buenos Aires (1892-década de 1930)", Anuario de la Escuela de Historia, UNR, Rosario, № 28, ISSN 1853-8835, pp. 15-38.

Lierbscher, A. (1989) "Institutionalization and evangelization in the Argentine church: Cordoba under Zenon Bustos, 1905-1919”, The Americas, 45:3.

Mauro, D. (2015) “El mutualismo católico en Argentina: El Círculo de Obreros de Rosario en la primera mitad del siglo XX”, Historia Crítica, Bogotá, nr. 55.

McGee Deutsch, S. (2003) Contrarrevolución en la Argentina, 1900-1932. La Liga Patriótica Argentina, EUNQ, Bernal.

Nuñez, M. V. (2017) "Pensar la Reforma a través de un Congreso de Librepensamiento", XVIJornadas Interescuelas/Departamentos de Historia, Mar del Plata, Universidad Nacional de Mar del Plata.

Pianetto, O. (1991) “Coyuntura histórica y movimiento obrero. Córdoba, 19171921", Estudios Sociales, Nr. 1, UNL, Santa Fe, pp. 87-106.

Rapalo, M. E. (2012) Patrones y obreros. La ofensiva de la clase propietaria, 19181930, Siglo XXI Editores, Buenos Aires.

Río, M. E. (1967) "Apuntes históricos sobre la Sociedad de Beneficencia de Córdoba (1856-1906)", en Córdoba, su fisonomía, su misión. Escritos y discursos, UNC, Córdoba.

Schenone, G. (2011) "El accionar del estudiantado católico en la UNC durante la Reforma Universitaria de 1918", Modernidades, FFyH-UNC, Disponible en https://ffyh.unc.edu.ar/modernidades/el-accionar-del-estudiantado-catolico-enla-unc-durante-la-reforma-universitaria-de-1918/

Vagliente, P. (2015) Asociativa, movilizada, violenta. La vida pública en Córdoba, 1850-1930, Tomos I y II, EDUVIM, Villa María. 
Reformismo universitario y movilización laicista ante "La Gran Colecta Nacional Pro Paz Social" en Córdoba (Argentina)

Vidal, G. (2010) "Intentos de centralización desde el Papado: la Unión Popular Católica Argentina en Córdoba”, en Vidal. G. y Blanco, J. (eds.) Catolicismo y política en Córdoba, siglos XIX $\mathrm{X} X X$, Ferreryra Editor, Córdoba.

Vidal, G. (2016) “'El nuevo catolicismo'en Córdoba durante las primeras décadas del siglo XX", Anuario de la Escuela de Historia, UNR, Rosario, № 28, ISSN 1853-8835, pp. 39-68.

Tcach, C. (2012) "Movimiento Estudiantil e intelectualidad reformista en Argentina (1918-1946)", Cuadernos de Historia, Nr. 37, Dpto. de Ciencias Históricas, Universidad de Chiles, pp. 131 - 157.

Recibido: 15/06/2020

Evaluado: $21 / 07 / 2020$

Versión Final: 26/08/2020 